\title{
Synthesis and Structural Characterization of New Macrocyclic Ester. Study as an Immobilization Agent for Determination of Lead by Anodic Stripping Voltammetry
}

\author{
Juan F. Torres ${ }^{1}$, Andreas Reiber ${ }^{1}$, Mario Macías ${ }^{1}$, Olimpo García-Beltran, \\ Edgar Nagles ${ }^{2, *}$ and John Hurtado ${ }^{1, *}$ \\ ${ }^{1}$ Department of Chemistry, Universidad de los Andes, Carrera 1 No. 18A-12, Bogotá, Colombia \\ ${ }^{2}$ Faculty of Natural Sciences and Mathematics, Universidad de Ibagué, Carrera 22 Calle 67, \\ Ibagué730001, Colombia \\ *E-mail: jj.hurtado@uniandes.edu.co, edgar.nagles@unibague.edu.co
}

doi: $10.20964 / 2017.04 .40$

Received: 27 December 2016 / Accepted: 19 February 2017 / Published: 12 March 2017

\begin{abstract}
New macrocyclic ester (L) was yielded through reaction of catechol with isophthaloylchloride and isolated as white solid, air stable at room temperature. $\mathrm{L}$ was characterized by melting point, mass spectra, FTIR and NMR $\left({ }^{1} \mathrm{H},{ }^{13} \mathrm{C}\right)$ spectroscopy. The molecular structure was determined by singlecrystal X-ray diffraction. The macrocyclic compound was evaluated to determine ultra-trace concentrations of $\mathrm{Pb}$ (II) by anodic stripping voltammetry in the presence of $\mathrm{Cd}(\mathrm{II})$. The method is based on the formation of a complex between lead and the macrocyclic ester, immobilized on a vitreous carbon electrode, allowing the oxidation of lead by voltammetric scan, using square wave modulation method. Anodic peak current was observed at $-0.20 \mathrm{~V}$ for $\mathrm{Pb}(\mathrm{II})$. Under the best experimental conditions ( $\mathrm{pH} 4.0$; $\mathrm{L}$ concentration $10.0 \mathrm{mmol} \mathrm{L}^{-1}$; accumulative potential (Eacc) $-0.8 \mathrm{~V}$ and accumulative time (tacc) of $60 \mathrm{~s}$ ) anodic peak current was proportional to the $\mathrm{Pb}$ (II) concentration up to $80.0 \mu \mathrm{g} \mathrm{L}^{-1}$, with a detection limit $(3 \sigma)$ of $0.33 \mu \mathrm{g} \mathrm{L}^{-1}$. The proposed method was validated by determining $\mathrm{Pb}(\mathrm{II})$ in model solution with ultra-pure water with satisfactory results.
\end{abstract}

Keywords: Macrocyclic ester, modified electrode, lead, anodic stripping voltammetry

\section{$\underline{\text { FULL TEXT }}$}

(C) 2017 The Authors. Published by ESG (www.electrochemsci.org). This article is an open access article distributed under the terms and conditions of the Creative Commons Attribution license (http://creativecommons.org/licenses/by/4.0/). 